\title{
Viewpoint: "Invisible colleges" and citation clusters in stocking rate research
}

\author{
RICHARD H. HART
}

\begin{abstract}
Author is range scientist, USDA, Agricultural Research Service, High Plains Research Station, 8408 Hildreth Road, Cheyenne, Wyo. 82009.
\end{abstract}

\begin{abstract}
Research on the response of livestock gain to stocking rate tends to cluster into 5 "invisible colleges", represented by 5 citation networks which only occasionally intersect. Each college is built around a paradigm of the stocking rate-gain response as developed in 2 key papers sharing 1 or more authors. Researchers tend to cite the paradigm developed by authors in their field of research or in their geographic area. Therefore conficting pardigms have existed side-by-side for decades, an unusual occurrence in most fields of science. Research is needed to critically evaluate the empirical and conceptual soundness of these paradigms.
\end{abstract}

Key Words: citation analysis, solidarity groups, sociology of science

The term "invisible college" appears to have been coined by the British natural philosopher Robert Boyle. Boorstin (1983) writes "...in 1656 ... Boyle himself had already christened this informal companionship of scientific enthusiasts wherever they were as the Invisible College." This invisible college became the nucleus of the Royal Society, founded in 1661.

Later the term "invisible college" came to symbolize divisions within science or within a field of science. Crane (1972) revived the term "invisible colleges" to define the communications networks linking nonintersecting sub-groups, each containing a few very productive scientists and many less productive ones.

Mullins (1968) and Griffith and Mullins (1972) refer to Crane's nonintersecting sub-groups as "solidarity groups," which they characterise as small, coherent, activist, and voluntarily and selfconsciously organized. They provide loose but effective communication networks within a team of students and junior colleagues headed by a productive researcher.

Cairns (1980) agrees that any discipline "is subdivided into loose networks of scientists with varying degrees of cohesiveness and continuity." Hagstrom (1965) concluded that strong leaders, "whose brilliance and skill lead others to emulate them," are the nucleus around which "monasteries" form.

In this paper, "invisible colleges" in stocking rate research are defined by nonintersecting or seldom-intersecting citation networks (Price 1965 and 1976), each based on 2 key publications by an individual or team. These publications in turn define a paradigm or hypothesis concerning the relationship between grazing animal gains and stocking rate. This central paradigm may be derived conceptually as consistent with known theories, or empirically as fitting experimental data. Paradigms may be accepted for empirical or conceptual reasons, or for other reasons related to geography, training, or professional association.

\footnotetext{
Manuscript accepted 12 Dec. 1992.
}

\section{Development of Stocking Rate Theory}

Stocking rate theory deals with determining the shape of the stocking rate-animal gain response curve and calculating the parameters of the curve for various pasture and animal types. The theory provides a basis for the design and interpretation of grazing studies, and input-output functions for economic analysis. The growth of stocking rate theory, as mapped by citations of previous publications, is plotted in Figure 1.

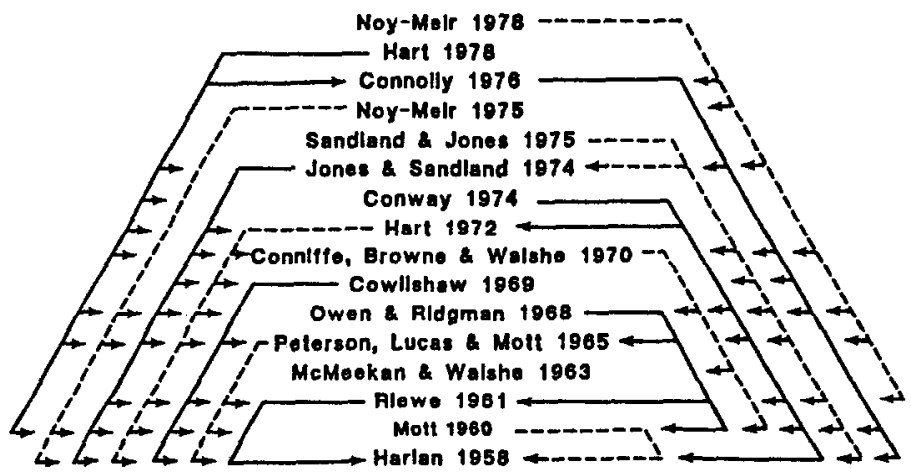

Fig. 1. Development of stocking rate-animal gain theory; "citation pyramid." Solid or broken lines and arrows point from citing paper to cited papers.

Harlan (1958) plotted "a hodge-podge of (gain per animal) data" as a double exponential function of stocking rate. Riewe (1961), using much of the same data, concluded that gain per head of cattle increased linearly with decreasing stocking rate, except at very low stocking rates where it might remain constant or even decline. Harlan (1958) and Riewe (1961) were cited by many other researchers in stocking rate theory, but were seld om cited by those doing stocking rate experiments, so did not found "invisible colleges."

Mott (1960) calculated that the ratio of gain per animal to gain per animal at optimum grazing pressure was a power function of the ratio (stocking rate)/(stocking rate at optimum grazing pressure). He did not define optimum grazing pressure, but noted that it was between that producing maximum gain per animal and that producing maximum gain per unit area. Petersen, Lucas, and Mott (1965) concluded that gain per animal was a convex, not a concave, function of stocking rate, at rates above a critical stocking rate.

McMeekan and Walshe (1963) did not attempt to express gain or milk production as a function of stocking rate or grazing pressure, but noted that "increase in stocking rate does not depress 
production per animal until a certain level of stocking is reached," and defined optimum grazing pressure as that where production per animal is $10-12 \%$ less than the maximum. Conniffe, Browne, and Walshe (1970) concluded production per animal was a sigmoid function of stocking rate when stocking rate exceeded that at maximum production per animal.

Owen and Ridgman (1968) accepted the curve of Petersen, Lucas, and Mott (1965). Cowlishaw (1969) demonstrated a linear decline in gain per animal with increasing stocking rate, but found no evidence for a critical stocking rate, or a stocking rate below which gain remains constant, in the data sets he examined. Owen and Ridgman (1968) and Cowlishaw (1969) were cited by most later theoreticians but did not receive enough other citations to found "colleges." Conway (1974) concluded on conceptual and mathematical grounds that gain per animal at stocking rates greater than the critical stocking rate must be a linear function of effective stocking rate or the ratio of actual stocking rate to critical stocking rate, but was seldom cited.

Jones and Sandland (1974) and Sandland and Jones (1975) examined data from several grazing trials with cattle on tropical pastures and concluded that gain per animal decreased linearly with increasing stocking rate over a range of 0.18 to 2.0 times optimum stocking rate, or the stocking rate at which gain per unit area was maximum. Gain per animal was half of maximum at optimum stocking rate, and gains per animal and per area dropped to zero at twice the optimum stocking rate. Hart et al. (1988a) pointed out that the former was true only if no critical stocking rate existed.

Hart (1972) argued that expressing gains as a function of grazing pressure, not stocking rate, allowed researchers to combine data from several years differing in the amount of forage produced. Unfortunately, he expressed gain per animal as a hyperbolic function of the reciprocal of grazing pressure, obscuring the fact that it is a linear function of grazing pressure. Hart (1978) clarified this point, demonstrated the existence of a critical grazing pressure, and showed that a series of instantaneous curves of the form proposed by Petersen, Lucas, and Mott (1965) collapse into linearity when combined over a grazing season.

Noy-Meir $(1975,1978)$ is somewhat of a special case because he did not address the gain-stocking rate relationship directly. But he showed how it could be derived from predator-prey graphs and cited many of the earlier stocking rate theoreticians. Hart (1989) developed SMART from predator-prey graphs and again showed how the gain-stocking rate relationship could be derived from it.

The forms of several stocking rate response curves are shown in Figure 2 (Hart 1978). Other curves have been proposed but have not yet been widely applied (Willms et al. 1986, Heitschmidt and Taylor 1991).

\section{Methods}

Through the Science Citation Index, 5 "invisible colleges" were identified. Each was built around 2 key papers which were cited far more often than the average paper and which continued to be cited for 10 or more years after publication. About $90 \%$ of scientific papers are never cited at all (Garfield 1983). Of those papers cited at least once in the Index from 1961 through 1982, only $10 \%$ were cited 10 or more times and only $3 \%$ were cited 25 or more times (Garfield 1985).

The Mott college was built on citations of papers by Mott (1960) and Petersen, Lucas, and Mott (1965). The Walshe college cited McMeekan and Walshe (1963) and Conniffe, Browne, and Walshe (1970). The Jones college cited Jones and Sandland (1974) and Sandland and Jones (1975). The Noy-Meir college cited Noy-Meir (1975 and 1978). A smaller group cited Hart (1972 and 1978); a

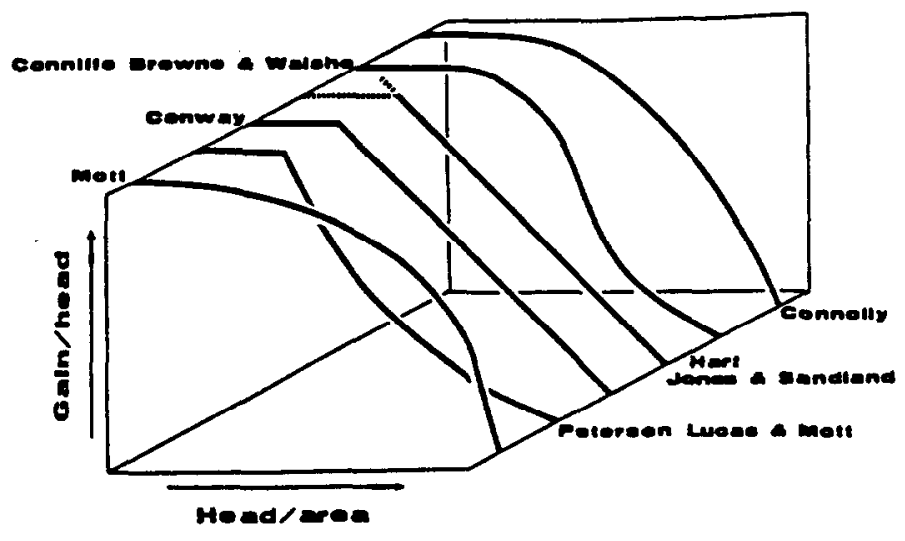

Fig. 2. Proposed relationships between stocking rate and liveweight gain per animal (Hart 1978).

colleague suggested this should be called the Hart "community college."

Numerous other publications proposed paradigms for the stocking rate-gain relationship but, as noted above, they were never sufficiently accepted to serve as foundations of colleges. However, they were usually cited in the core papers of the colleges. These included Harlan (1958), Riewe (1961), Owen and Ridgman (1968), Cowlishaw (1969), Conway (1974), and Connolly (1976a, 1976b, 1976c).

Citations of each of the key papers were identified from the Science Citation Index through 1991, which covers papers published through the first 8 to 9 months of 1991. This procedure incompletely identified the impact of a "college." The Index does not include some journals and rarely includes books or conference proceedings. Citations of the Hart papers, in which the author takes a keen personal interest, include at least 22 such citations in addition to the 25 in the Index. MacRoberts and MacRoberts (1989) estimated that authors seldom cite more than half the papers which support basic assumptions or provide background knowledge, and often cite irrelevant papers. Nor do citation counts provide recognition for informal influences, or distinguish between affirmative and negative citations.

To minimize effects of blatant self-promotion (MacRoberts and MacRoberts 1989), self-citations (citations in any publication authored or co-authored by 1 or more authors of a key paper) were excluded. In Hart's case, this included 13 citations.

Figures were then constructed to show the frequency of citation by years of key papers within each college, number of publications citing papers from 1 or more colleges, and the distribution of citations among journals.

\section{Results and Discussion}

The first of the 2 papers forming the nucleus of each college was first cited 1 year (Mott 1960, Jones and Sandland 1974), 2 years (Hart 1972), or 3 years after publication (McMeekan and Walshe 1963, Noy-Meir 1975). Most continue to be cited today, 17 to 32 years after they first appeared (Fig. 3). Neither of the Walshe papers was cited in 1990 or 1991 , but this may be only a temporary lapse. The Jones papers were not cited in 1983 or 1984 , but thereafter exceeded their previous citation rates. The citation record of Hart exhibits several gaps, but these papers were cited at their highest rate in 1990, the last year for which a full citation record is available.

The citation network of 4 of the colleges (Fig. 4) shows 241 citations from 194 papers. Of these, 156 papers cited only a single college, 29 cited 2 colleges, and only 9 cited 3 colleges; none cited all 4 colleges. The most frequently cited combination was that of Mott 

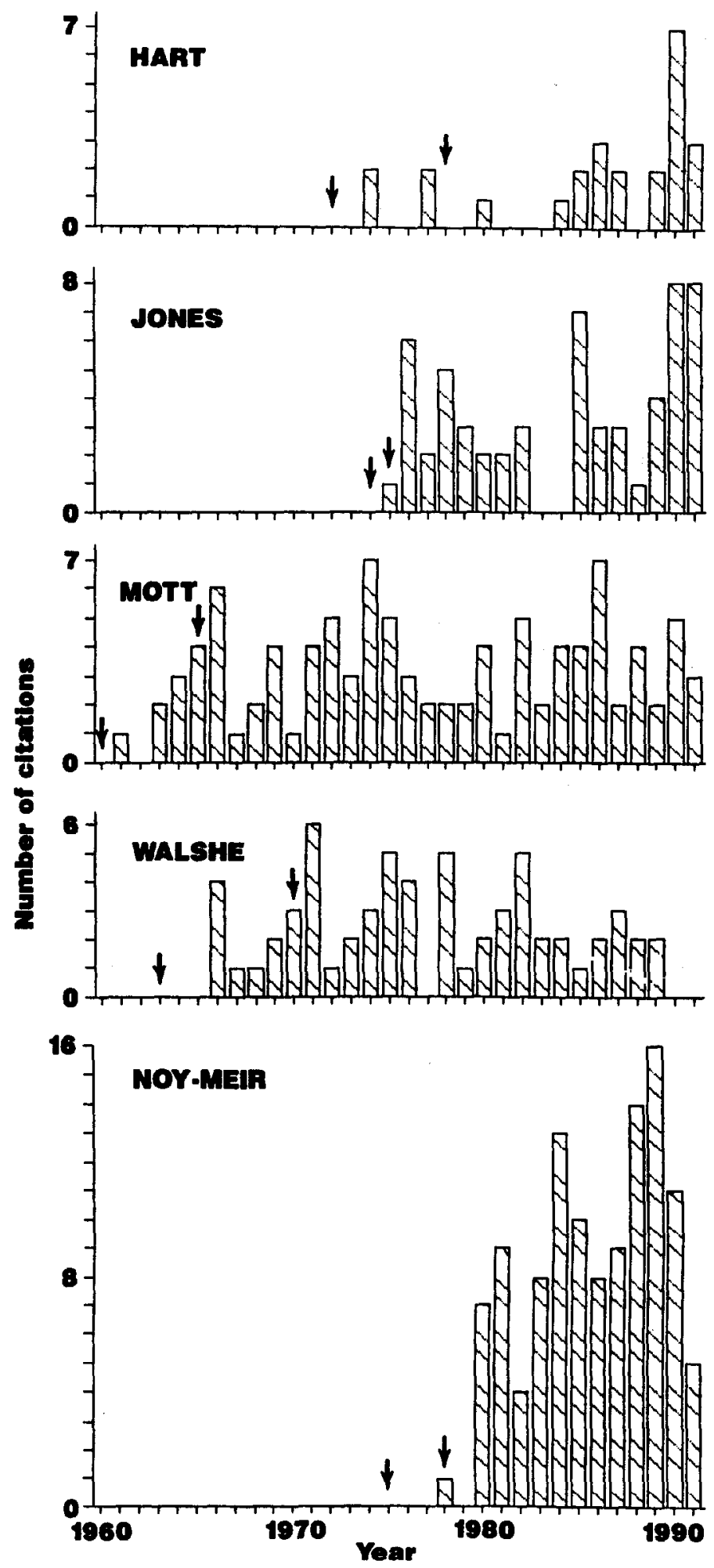

Fig. 3. Number of citations per year of key papers in 5 "invisible colleges" in stocking rate research. Arrows indicate years in which key papers were published.

and Walshe (11 citations); no other combination of 2 or 3 colleges was cited more than 5 times.

Only 32,35 , and $28 \%$ of the papers citing Jones, Walshe, and Mott, respectively, cited other colleges. In contrast, $56 \%$ of the papers citing Hart also cited 1 or 2 other colleges. Jones was cited in $20 \%$ of the papers citing Hart, reflecting the similarity of their

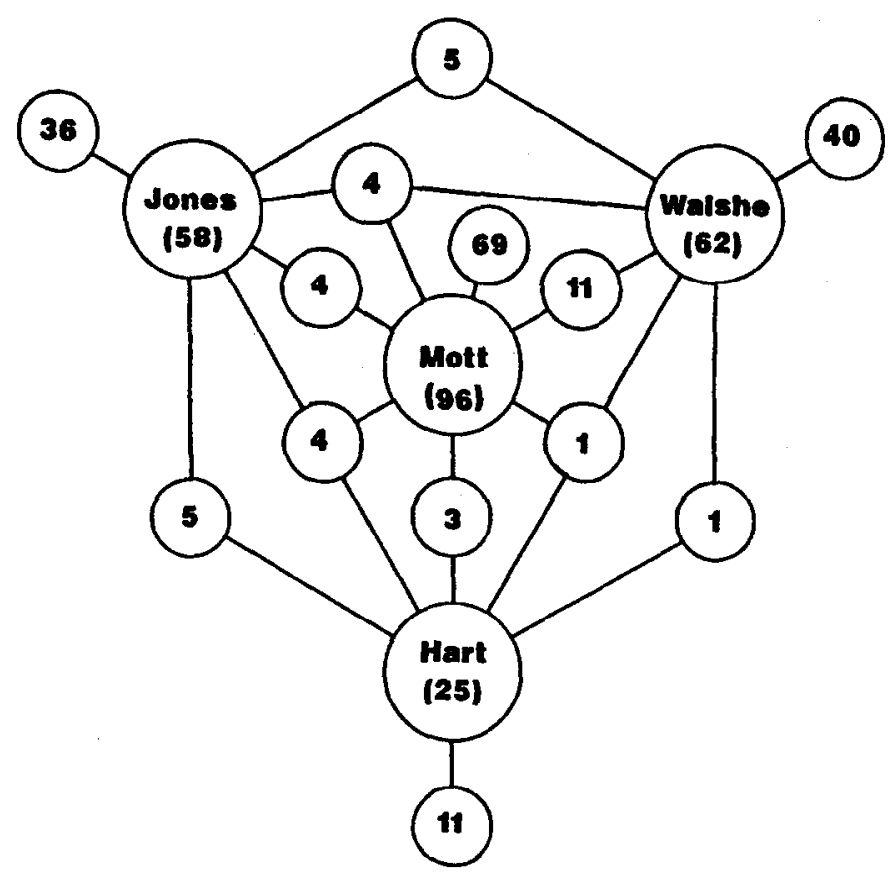

Fig. 4. Citation network of 4 "invisible colleges" in stocking rate research. Lines connect citing papers (small circles) with cited colleges (large circles). Numbers in small circles indicate number of papers citing a college or group of colleges; numbers in parentheses in large circles indicate total papers citing a college.

paradigms. Both propose a linear stocking rate response, but differ in that Hart proposes a constant gain at low stocking rates.

Noy-Meir was almost completely isolated from the other colleges. Only 6 of the 115 papers citing Noy-Meir also cited 1 or more of the other colleges.

Citations by journal or journal category are shown in Figure 5. Only journals or categories containing more than $4 \%$ of the citations from a college are identified.

Citations of Jones are concentrated in the tropics, Australia, New Zealand, and the British Isles. Of all citations, $14 \%$ appear in Tropical Grasslands and 16\% in Australian Journal of Agricultural Research or Australian Journal of Experimental Agriculture, with an additional $5 \%$ in other journals from Australia or New Zealand. Journal of Agricultural Science, Grass and Forage Science, and Irish Journal of Agricultural Research account for $14 \%$ of Jones citations.

The Walshe college is even more strongly concentrated in the British Isles: 45\% of its citations are in Journal of Agricultural Science, Grass and Forage Science, or Irish Journal of Agricultural Research, and 3\% in other Irish and UK journals. Another 13\% of citations appear in Australian and New Zealand journals.

Mott also is cited frequently in Grass and Forage Science (15\%), Journal of Agricultural Science (16\%), and other Irish and UK journals (7\%). Agronomy Journal and Journal of Production Agriculture, journals of the American Society of Agronomy, provide $9 \%$ of Mott's citations.

Citations of Jones, Mott, and Walshe are predominantly in agricultural journals. Mott has the highest frequency of citation in ecology and systems journals with $8 \%$ in Agricultural Systems and Journal of Applied Ecology. Jones is not often cited in animal and dairy science journals but Walshe (18\% in Journal of Animal Science, Animal Production and others) and Mott (10\%) are.

Hart's citations also are mainly in agricultural journals, but with a much higher percentage of citations in Journal of Range Man- 

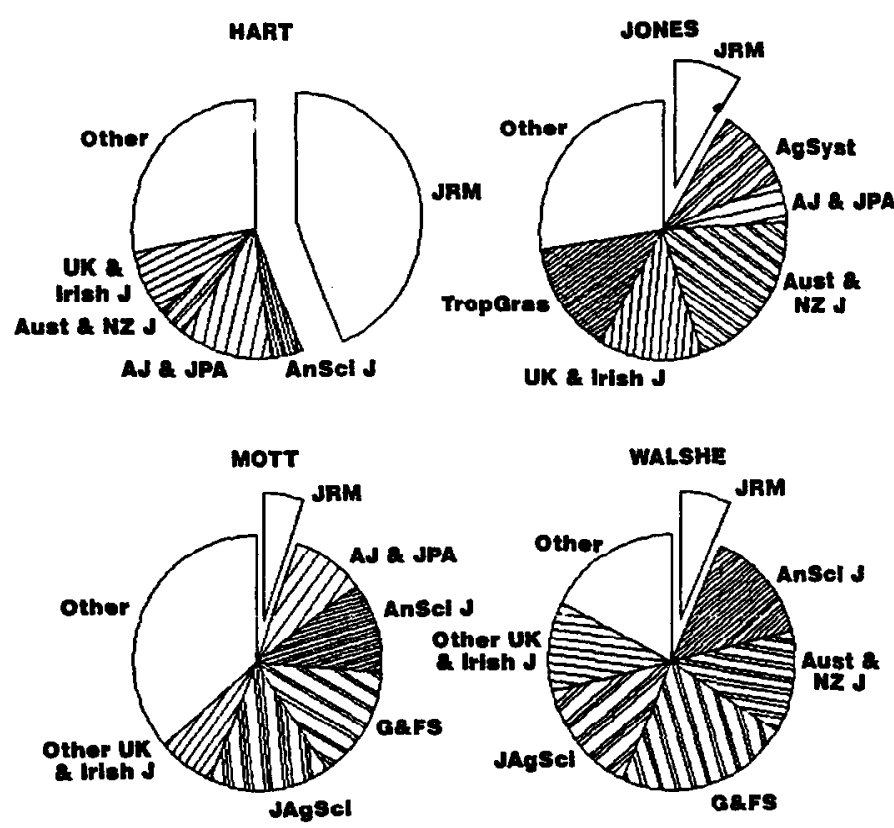

MOY-MEIR

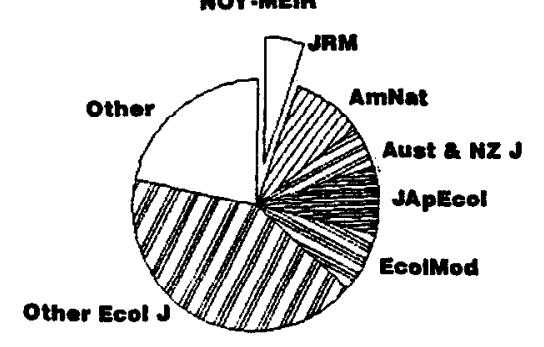

Fig. 5. Journals and groups of journals citing papers from 5 "invisible colleges" in stocking rate research. JRM = Journal of Range Management, AgSyst = Agricultural Systems, AJ \& JPA = Agronomy Journal and Journal of Production A griculture, AmNat = American Naturalist, AnSci $J=$ animal and dairy science journals, Aust \& NZ J = journals from Australia and New Zealand, EcolMod = Ecological Modeling, Ecol J = ecological journals, G\&FS = Grass and Forage Science and its predecessor Journal of the British Grassland Society, JAgSci = Journal of A gricultural Science, JApEcol = Journal of Applied Ecology, TropGras = Tropical Grasslands, and UK \& Irish J = agricultural journals from United Kingdom and Ireland.

agement, $44 \%$, than any other college. Agronomy Journal and Journal of Production Agriculture account for another $12 \%$ of citations, as do journals from Ireland, United Kingdom, Australia, and New Zealand.

Citations of the Noy-Meir college are not concentrated geographically, but by discipline. American Naturalist (10\%) Ecological Modeling (8\%), Journal of Applied Ecology (9\%), and "Other ecological journals" (42\%) account for $69 \%$ of his citations. The last category includes Ecology, Holarctic Ecology, Journal of Animal Ecology, Oecology, Oikos, and Theoretical and Population Biology, each with 3 to $4 \%$ of total citations, plus several other journals citing Noy-Meir less frequently. Noy-Meir is seldom cited in agricultural journals, which except for Journal of Range Management $(5 \%)$ are included in "Other." This category also includes Journal of Wildlife Management, accounting for $4 \%$ of NoyMeir's citations but none from the other 4 colleges.

Omissions in the citation record are revealing. Of the 303 papers (109 citing only Noy-Meir and 194 citing 1 or more of the other colleges), only 2 are from economics journals. One would expect economists to use stocking rate-gain response functions as input- output functions in economic analysis of livestock grazing, but they rarely do so.

Only 22 papers citing any college ( $11 \%$ of the total) appeared in animal or dairy science journals. Animal and dairy scientists tend to publish the results of grazing studies in grasslands, range, agronomic, or general agricultural journals (Agronomy Journal, Australian Journal of Experimental Agriculture, Grass and Forage Science, Journal of Agricultural Research, Journal of Range Management, and Tropical Grasslands, for example).

Kuhn (1970) concludes that new paradigms replace old when the new can explain anomalies between observation and the old paradigm. But we see conflicting paradigms of the stocking rate-gain response co-existing and frequently cited for decades, although conflicting paradigms are seldom cited in the same paper except for reviews. Citation of a particular paradigm may reflect a congruence of geographic location and field of research between citer and cited rather than the content of the paradigm.

Noy-Meir is an ecologist, and is cited mostly in ecology journals. Founders of the Jones, Mott, and Walshe colleges are agronomists and are usually cited in agricultural journals. Hart is a range scientist and is cited mostly in Journal of Range Management.

Jones and Sandland work at St. Lucia, Queensland, Australia, Jones in the Division of Tropical Agronomy. They are cited most often in Tropical Grasslands and in Australian and New Zealand journals. But the British Empire lives; they are also cited frequently in journals from the British Isles. Walshe worked in New Zealand when McMeekan and Walshe (1963) was published, and in Ireland when Conniffe, Browne and Walshe (1970) was published. Most of Walshe's citations are from journals originating in Ireland and the UK, with a significant fraction in Australian and New Zealand journals. Mott, although an American, is frequently cited in Irish and UK as well as American journals, perhaps because Mott (1960) was published in International Grassland Congress Proceedings.

All these paradigms have empirical value. Some framework is essential for generalization of the results of grazing trials. Without such generalizations, we are left with what Goodall (1960) derided as studies "which establish only that in 'County Cornstalk' in 1957, 36-inch spacing was better than 42 inches-or vice versa or more or less." Generalizations allow experimental results to be applied to situations which do not exactly mimic the situation of the original experiment.

Research is needed to critically evaluate the conceptual value of the different paradigms of the stocking rate response. The most carefully designed stocking rate/grazing pressure studies may not be able to distinguish empirically between concave, convex, and linear response curves, because variability may be too great. Greater knowledge of the basic biological processes involved in grazing may provide a conceptual basis for determining the shape of the curve. However, Levins (1966) cautions "There is always room for doubt as to whether a result depends on the essentials of a model or on the details of the simplifying assumptions."

Nevertheless, models in conjunction with field research provide useful insights into the shape of the response curve and the impact of variables other than stocking rate or grazing pressure on the parameters of the curve. For example, Hart and Hanson (1993) used the SPUR II model to generate grazing pressure response curves. They found that the curves followed the form proposed by Hart (1978) and that the major factors affecting the parameters of the curve were length of grazing season and forage digestibility, with initial weight of the grazing animals a minor factor.

\section{Literature Cited}

Boorstin, D.J. 1983. The Discoverers. Harry N. Abrams, Inc., Publishers, N.Y.

Cairns, J. Jr. 1980. The Recovery Process in Damaged Ecosystems. Ann Arbor Science Publ. Inc., Ann Arbor, Mich. 
Conniffe, D., D. Browne, and M.J. Walshe. 1970. Experimental design for grazing trials. J. Agr. Sci. 74:339-342.

Connolly, J. 1976a. The design of grazing experiments. 1. A general linear model for the gain-stocking rate relationship. Irish J. Agr. Res. 15:355-364.

Connolly, J. 1976b. The design of grazing experiments. 2. A simple linear model for the gain-stocking rate relationship. Irish J. Agr. Res. 15:365-374.

Connolly, J. 1976c. Some comments on the shape of the gain-stocking rate curve. J. Agr. Sci. 86:103-109.

Conway, A.G. 1974. A production function for grazing cattle. 3. An estimated relationship between rate of liveweight gain and stocking rate for grazing steers. Irish J. Agr. Econ. Rur. Soc. 5:43-55.

Cowlishaw, S.J. 1969. The carrying capacity of pastures. J. Brit. Grassl. Soc. 24:207-214.

Crane, D. 1972. Invisible colleges. Univ. of Chicago Press, Chicago.

Garfield, E. 1983. How to use citation analysis for faculty evaluations, and when is it relevant? Parts 1 \& 2. Curr. Cont. 14(44):3-11 \& 14(45):3-12.

Garfield, E. 1985. Uses and misuses of citation frequency. Curr. Cont. $16: 2-8$.

Goodall, D.W. 1960. Quantitative effects of intraspecific competition: an experiment with mangolds. Bull. Res. Coun. Israel (D) 8:181-194.

Griffith, B.C. \& N.C. Mullins. 1972. Coherent social groups in scientific change. Science 112:959-964.

Hagstrom, W. 1965. The scientific community. Basic Books. N.Y.

Harlan, J.R. 1958. Generalized curves for gain per head and gain per acre in rates of grazing studies. J. Range Manage. 11:140-147.

Hart, R.H. 1972. Forage yield, stocking rate, and beef gains on pasture. Herb. Abstr. 42:345-353.

Hart, R.H. 1978. Stocking rate theory and its application to grazing on rangelands. p. 547-550 In: Hyder, D.N. (ed.) Proc. First Int. Rangeland Congr. Soc. Range Manage., Denver, Colo.

Hart, R.H. 1989. SMART: a Simple Model to Assess Range Technology. J. Range Manage. 42:421-424.

Hart, R.H., and J.D. Hanson. 1993. Managing for economic and ecological stability of range and range-improved grassland systems with the SPUR II model and the STEERISKIER spreadsheet. Proc. XVII Int. Grassl. Cong.: (in press).

Hart, R.H., M.J. Samuel, P.S. Test, and M.A. Smith. 1988a. Cattle, vegetation and economic responses to grazing systems and grazing pressure. J. Range Manage. 41:282-286.

Hart, R.H., J.W. Waggoner Jr., T.G. Dunn, C.C. Kaltenbach, and L.D. Adams. 1988b. Optimal stocking rate for cow-calf enterprises on native range and complementary improved pastures. J. Range Manage. $41: 435-441$
Heitschmidt, R.K., and C.A. Taylor Jr. 1991. Livestock production. p. 161-177. In: Heitschmidt, R.K., and J.W. Stuth (eds.) Grazing Management: An Ecological Perspective. Timber Press, Portland, Ore.

Jones, R.J. \& R.L. Sandland. 1974. The relation between animal gain and stocking rate. Derivation of the relation from the results of grazing trials. J. Agr. Sci. 83:335-342.

Kuhn, T. 1970. The structure of scientific revolutions (2nd ed.) Univ. of Chicago Press, Chicago.

Levins, R. 1966. The strategy of model building in population biology. Amer. Sci. 54:421-431.

MacRoberts, M.H., and B.R. MacRoberts. 1989. Problems of citation analysis: a critical review. J. Amer. Soc. Info. Sci. 40:342-349.

McMeekan, C.P. \& M.J. Walshe. 1963. The interrelationships of grazing method and stocking rate in the efficiency of pasture utilization by dairy cattle. J. Agr. Sci. 61:147-163.

Mott, G.0. 1960. Grazing pressure and the measurement of pasture production. p. 606-611 In: Proc. 5th Int. Grassl. Congr.

Mullins, N.C. 1968. The distribution of social and cultural properties in informal communication networks among biological students. Amer. Soc. Rev. 33:786-797.

Noy-Meir, I. 1975. Stability of grazing systems: an application of predatorprey graphs. J. Ecol. 63:459-481.

Noy-Meir, I. 1978. Grazing \& production in seasonal pastures: analysis of a simple model. J. Appl. Ecol. 15:809-820.

Owen, J.B., and W.J. Ridgman. 1968. The design and interpretation of experiments to study animal production from grazed pasture. J. Agr. Sci. 71:327-335.

Peterson, R.G., H.L. Lucas, and G.O. Mott. 1965. Relationship between rate of stocking and per animal and per acre performance on pasture. Agron. J. 57:27-30.

Price, D.J. de S. 1965. Networks of scientific papers. Science 149:510-515.

Price, D.J. de S. 1976. A general theory of biblometric and other cumulative advantage process. J. Amer. Soc. Info. Sci. 27:292-306.

Riewe, M.E. 1961. Use of the relationship of stocking rate to gain of cattle in an experimental design for grazing trials. Agron. J. 53:309-313.

Sandland, R.L., and R.J. Jones. 1975. The relation between animal gain and stocking rate in grazing trials: an examination of published theoretical models. J. Agr. Sci. 85:123-128.

Willms, W.D., S. Smoliak, and G.B. Schallje. 1986. Cattle weight gains in relation to stocking rate on rough fescue grassland. J. Range Manage. 39:182-187. 